\title{
Verification of Secondary Electron Generated by Head Screw in Gamma Knife Using Monte Carlo N-Particle Simulation
}

\author{
Heesoo Kim ${ }^{1[}$, Jeong-Woo Lee ${ }^{1,2(1)}$ \\ 'Department of Convergent Medical Physics, Graduate School of Engineering, Konkuk University, ${ }^{2}$ Department of Radiation Oncology, \\ Konkuk University Medical Center, Seoul, Korea
}

Received 2 June 2020

Revised 16 June 2020

Accepted 17 June 2020

Corresponding author

Jeong-Woo Lee

(polirain@kuh.ac.kr)

Tel: 82-2-2030-5393
Purpose: The interaction of various substances inserted into the human body and radiation can confirm the radiation enhancement effect. A Leksell frame inserted into the human body for gamma knife treatment will cause not only pain and inconvenience to the patient, but also additional exposure to the patient's normal tissues. In this study, we attempt to confirm the additional exposure caused by the interaction of the Leksell frame and thermoplastic mask, and ${ }^{60} \mathrm{Co}$ used for gamma knife treatment.

Methods: $\mathrm{A}{ }^{60} \mathrm{Co}$ energy of $1.17,1.33 \mathrm{MeV}$ is applied using Monte Carlo simulation, and fixation screws and thermoplastic mask are fabricated using aluminum and titanium alloy, and Carbon compounds.

Results: Results show a dose enhancement of up to $396.27 \%$ higher compared with that without a Leksell frame and up to $391.25 \%$ in thermoplastic mask.

Conclusions: Hence, appropriate treatment methods and materials must be used to reduce additional exposure to normal tissues.

Keywords: Gamma knife, Head screw, Secondary electron, Monte Carlo N-Particle

\section{Introduction}

High-energy radiation therapy aims to provide the maximum radiation to lesions while protecting normal organs. Radiation therapy methods for treating lesions include intensity-modulated radiation, image-guided radiation, and stereotactic radiation therapies [1]. Furthermore, radiosurgery using a linear accelerator equipped with an image guiding device has been developed in various forms and applied for clinical use. Furthermore, gamma knife radiosurgery using ${ }^{60} \mathrm{Co}$, a traditionally used sealed source, is continuously being upgraded.

In recent years, gamma knife radiosurgery has evolved into a form that is applicable for the effective treatment of head/neck and brain lesions. Moreover, it is useful in the treatment of multiple metastatic brain tumors caused by breast and lung cancers [2-8].

Generally, a gamma knife uses a ${ }^{60} \mathrm{Co}$ source, which has a half-life of $5.27 \mathrm{y}$. The ${ }^{60} \mathrm{Co}$ source is a nuclide emitting two gamma rays and one beta ray. It exhibits most peaks at 1.17 and $1.33 \mathrm{MeV}$ in gamma rays depending on energy spectrum analysis [9-11].

The ${ }^{60} \mathrm{Co}$ source has been shown to be a non-invasive method that focuses on high-dose radiation on lesions. However, to accurately localize lesions, magnetic resonance imaging and computed tomography images are required to 
delineate anatomical organ volumes and treatment targets for treatment planning [12]. At the beginning of image acquisition, a patient must be fixed invasively with screws of the Leksell frame. Additionally, gamma knife radiosurgery based on a fixed frame has proven effectiveness as a stereotactic operation that can maintain an error of less than 1 mm while the patient's posture is being fixed [13].

However, the patient may not only experience pain and inconvenience caused by a head screw inserted inside the human body, but also dangers associated with normal tissues being exposed to radiation [14].

Hwang et al. [15] reported that nanoparticle doses of various materials inserted for radiation therapy can be up to 3.11 and 1.04 times more in kilovolt and megavolt X-rays, respectively. Furthermore, it was demonstrated that larger gold nanoparticles and lower incident energies are more closely related to secondary electron generation [16]. Mesbahi et al. [17] stated that the insertion of gold nanoparticles increased dose enhancement. Furthermore, Cheung et al. [18] reported a dose enhancement of up to $10 \%$ near a

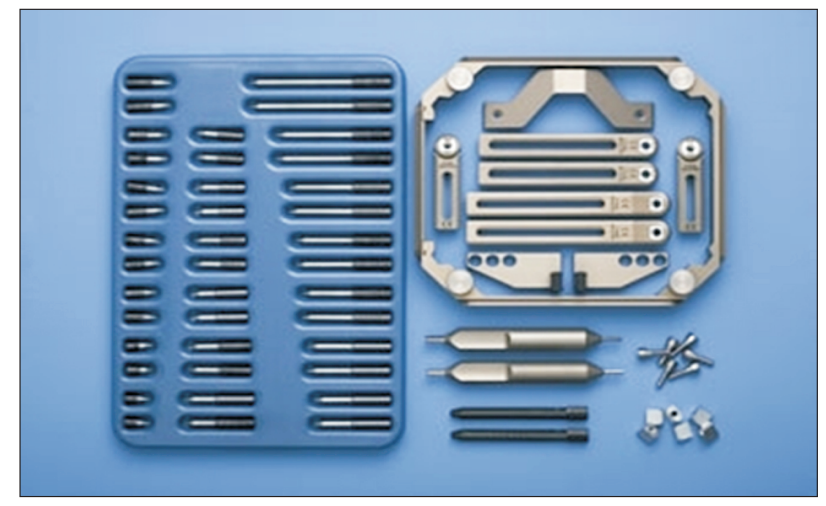

Fig. 1. Radiosurgery of head frame and head screw. platinum implant.

In this study, we evaluated the additional exposure caused by the interaction of ${ }^{60} \mathrm{Co}$ gamma rays with each screw inserted in the human body and thermoplastic mask for fixing the patient using the Monte Carlo method.

\section{Materials and Methods}

The Monte Carlo N-Particle code version 2.7.0 (Los Alamos National Laboratory, USA) based on the Monte Carlo technique was used. Fixation screws and a thermoplastic mask were simplified to cylindrical and rectangular shapes based on schematics from the data sheet (see Fig. 1). Monte carlo simulations for screws were performed in a water phantom at $5 \mathrm{~mm}$ intervals from 45 to $65 \mathrm{~mm}$. Calculations were performed starting from the build-up point of $5 \mathrm{~mm}$ with/without a thermoplastic mask measuring 2.4 and 3.2 mm (Fig. 2). The point of interest (Tally) was assigned with the screws and thermoplastic mask.

The composition was simulated with titanium alloy (4.54 $\left.\mathrm{g} / \mathrm{cm}^{2}\right)$, aluminum alloy $\left(2.85 \mathrm{~g} / \mathrm{cm}^{2}\right)$, and thermoplastic mask $\left(1.1 \mathrm{~g} / \mathrm{cm}^{2}\right)$, separately. The energy was defined as a source of 1.17 and $1.33 \mathrm{MeV}$ photons and ${ }^{60} \mathrm{Co}$ energy peaks were considered [19]. The distance of the source was specified at $165 \mathrm{~mm}$ based on the schematics of the Leksell knife. Additionally, the distance between the source and phantom was composed of air defined according to an International Commission on Radiation Units and Measurements report 44 [20].

An F4 tally was performed as specified by photon particle transport to count the electron fluence per unit area (particle $/ \mathrm{mm}^{2}$ ) [21-24]. To ensure that the statistical uncer- a

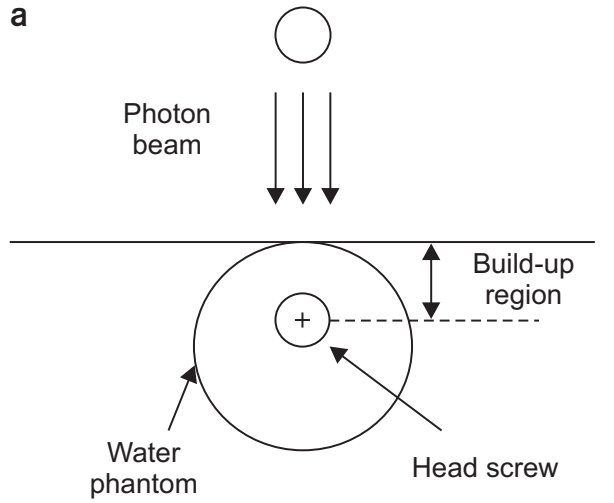

b

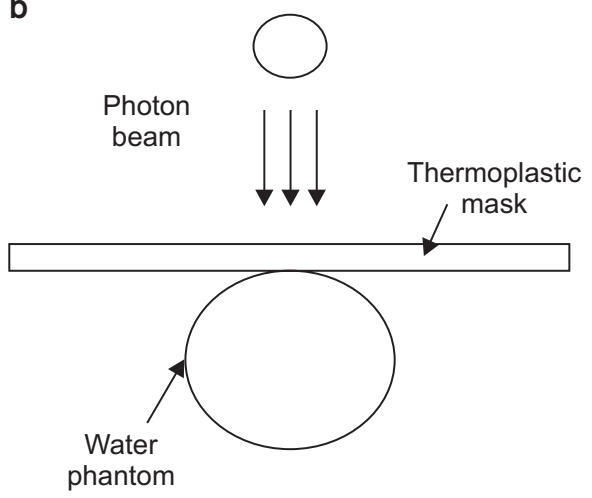

Fig. 2. Monte Carlo simulation geometry. (a) Schematics of fixed screw; (b) schematics of thermoplastic mask. Simulation geometry was simplified for rendering of head, fixing screws, and thermoplastic mask; build-up region was $5 \mathrm{~mm}$. 
tainty remained within $5 \%$ in the simulation, the number of repetitions was performed $1 \times 10^{8}$ times (Fig. 3) [25].

\section{Results}

The results showed a relative increase in the number of secondary electrons based on the absence of fixed screws

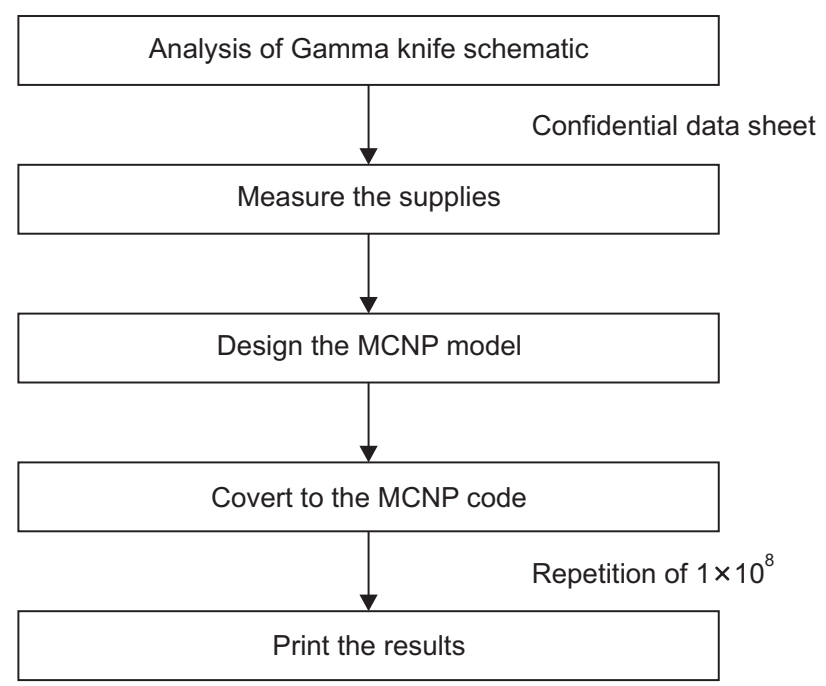

Fig. 3. Simulation process for MCNP coding. Based on the structure and supplies information of the Leksell gamma knife from a confidential data sheet, coding was performed for MCNP simulation; the number of repetition was specified as $1 \times 10^{8}$ to accommodate an uncertainty of less than 5\%. MNCP, Monte Carlo N-Particle. at a depth of $5 \mathrm{~mm}$. The larger the size and energy of the fixing screw in each energy point, the more secondary electrons appeared through the interaction with the radiation and screws. As shown in Table 1 for the titanium alloy, $278.39 \%$, 298.11\%, 315.66\%, 331.25\%, and 344.86\% more electrons were generated at lengths of 45, 50, 55, 60, and $65 \mathrm{~mm}$, respectively, in $1.17 \mathrm{MeV}$. For the case of $1.33 \mathrm{MeV}$, $279.61 \%$, 299.48\%, 317.57\%, 333.65\%, and 347.53\% more electrons were generated at lengths of 45, 50, 55, 60, and $65 \mathrm{~mm}$, respectively. Furthermore, as shown in Table 2 for the aluminum alloy, 309.77\%, 334.18\%, 356.21\%, 376.18\%, and $394.26 \%$ electrons were generated at lengths of 45,50 , 55,60 , and $65 \mathrm{~mm}$ in $1.17 \mathrm{MeV}$, respectively; and 310.13\%, $335.1 \%$, 357.44\%, 378.06\%, and 396.27\% more electrons were generated at lengths of 45, 50,55, 60, and $65 \mathrm{~mm}$ in 1.33 MeV, respectively. Furthermore, the occurrence of secondary electrons of aluminum alloy was more extensive than that of titanium alloy.

Electrons generated by the interaction between the radiation and the thermoplastic mask were measured. As shown in Table 3, electron generation increased by $264.69 \%$ and $391.25 \%$ for the 2.4 and $3.2 \mathrm{~mm}$ thermoplastic masks in $1.17 \mathrm{MeV}$, respectively. For $1.33 \mathrm{MeV}$, electron generation increased by $262.79 \%$ and $388.75 \%$ for the 2.4 and $3.2 \mathrm{~mm}$ thermoplastic masks, respectively.

Table 1. Amount of secondary electrons generated through interaction between radiation along each energy and length of titanium-alloy head screw (units: particle $/ \mathrm{mm}^{2}$ )

\begin{tabular}{ccccccc}
\hline Beam energy & Non head screw & $45 \mathrm{~mm}$ & $50 \mathrm{~mm}$ & $55 \mathrm{~mm}$ & $60 \mathrm{~mm}$ & $65 \mathrm{~mm}$ \\
\hline $1.17 \mathrm{MeV}$ & $3.2406 \mathrm{E}-02$ & $1.2262 \mathrm{E}-01$ & $1.2901 \mathrm{E}-01$ & $1.3470 \mathrm{E}-01$ & $1.3975 \mathrm{E}-01$ & $1.4416 \mathrm{E}-01$ \\
$1.33 \mathrm{MeV}$ & $3.2413 \mathrm{E}-02$ & $1.2300 \mathrm{E}-01$ & $1.2944 \mathrm{E}-01$ & $1.3530 \mathrm{E}-01$ & $1.4051 \mathrm{E}-01$ & $1.4501 \mathrm{E}-01$ \\
\hline
\end{tabular}

Table 2. Amount of secondary electrons generated through interaction between radiation along each energy and length of the aluminumalloy head screw (units: particle $/ \mathrm{mm}^{2}$ )

\begin{tabular}{ccccccc}
\hline Beam energy & Non head screw & $45 \mathrm{~mm}$ & $50 \mathrm{~mm}$ & $55 \mathrm{~mm}$ & $60 \mathrm{~mm}$ & $65 \mathrm{~mm}$ \\
\hline $1.17 \mathrm{MeV}$ & $3.2406 \mathrm{E}-02$ & $1.3279 \mathrm{E}-01$ & $1.4070 \mathrm{E}-01$ & $1.4784 \mathrm{E}-01$ & $1.5431 \mathrm{E}-01$ & $1.6017 \mathrm{E}-01$ \\
$1.33 \mathrm{MeV}$ & $3.2413 \mathrm{E}-02$ & $1.3289 \mathrm{E}-01$ & $1.4098 \mathrm{E}-01$ & $1.4822 \mathrm{E}-01$ & $1.5490 \mathrm{E}-01$ & $1.6080 \mathrm{E}-01$ \\
\hline
\end{tabular}

Table 3. Amount of secondary electrons generated through interaction between radiation along each energy and the thickness of the thermoplastic mask (units: particle $/ \mathrm{mm}^{2}$ )

\begin{tabular}{cccc}
\hline Beam energy & Non thermoplastic mask & $2.4 \mathrm{~mm}$ & $3.2 \mathrm{~mm}$ \\
\hline $1.17 \mathrm{MeV}$ & $3.2406 \mathrm{E}-02$ & $1.1815 \mathrm{E}-01$ & $1.5915 \mathrm{E}-01$ \\
$1.33 \mathrm{MeV}$ & $3.2413 \mathrm{E}-02$ & $1.1759 \mathrm{E}-01$ & $1.5842 \mathrm{E}-01$ \\
\hline
\end{tabular}



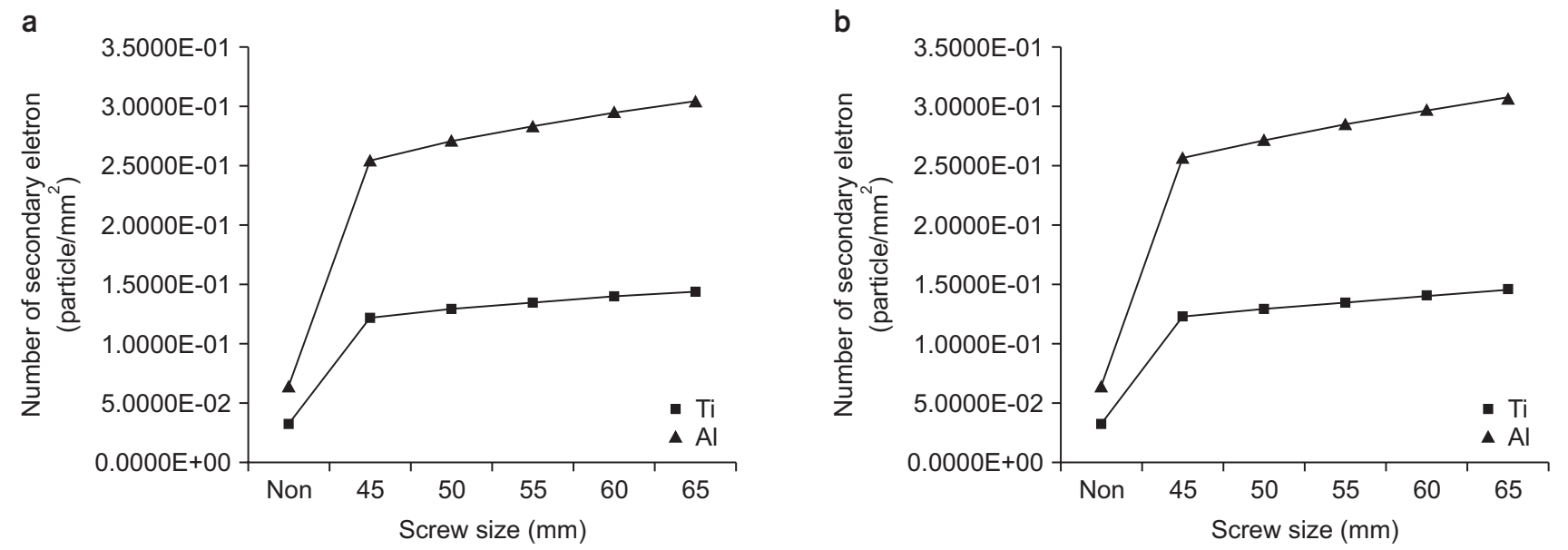

Fig. 4. Comparison of electron generation in titanium and aluminum alloy (a) $1.17 \mathrm{MeV}$, (b) $1.33 \mathrm{MeV}$. Based on the absence of fixing screws, secondary electron generation was compared by screw size and energy.

\section{Discussion}

According to the physical mechanism, the photoelectric effect is dominant in diagnostic X-rays using lower incident energies. Additionally, more secondary electrons are generated as the energy decreases and the atomic number of the medium increases. Furthermore, in high-energy radiation therapy, energy transfer occurs primarily through Compton scattering, which produces fewer secondary electrons than low-energy regions, such as diagnostics, because of its low dependence on the atomic number. However, it was demonstrated that the generation of reduced secondary electrons increased again when pair production began [26].

We performed a simulation based on the Monte Carlo method to evaluate the number of secondary electrons generated by fixed screws inserted into the human body during gamma knife treatment. In the study, as the size and energy of the screws used for fixation increased, the generation of secondary electrons increased up to $394.26 \%$ and $396.27 \%$ at 1.17 and $1.33 \mathrm{MeV}$, respectively.

Although differences in measured values may arise because of the build-up region and geometry structure, we identified concerns regarding further exposure due to materials inserted into the human body.

The results show that aluminum alloy yielded a more considerable dosage increase than titanium alloy because some of the scattered radiation was absorbed by the tita- nium alloy, which was higher in density (Fig. 4). Furthermore, in other gamma knife equipment using a thermoplastic mask, interactions between the source and mask may result in additional secondary electrons, which may contribute to additional exposure to normal tissues [27-30].

In this study, it is meaningful to obtain useful information regarding the increase in dose that could not be measured during radiation surgery; this can be performed by confirming the generation of secondary electrons according to the size and energy of the fixing screw inserted into the human body and the generation of secondary electrons according to each thickness of thermoplastic mask through simulations.

We attempted to confirm the trend of secondary electrons generated from a single source. From the trend, we can predict that more secondary electrons occur when the 201 sources of the gamma knife are used.

\section{Conclusions}

It was discovered in this study that the larger size and energy of fixing screws for fixing a patient's posture, the more secondary electrons appeared during gamma knife treatment. In addition, the appropriate methods and materials for each treatment should facilitate the reduction in radiation exposure to normal tissues [31,32], e.g., by moving the head screw fixation point and removing part of the thermoplastic mask. 
Furthermore, carbon fiber fixing screws, such as polyaxial screws, are mainly used to fix bones in orthopedic and neurosurgical operations $[33,34]$. The number of electrons produced due to interactions with radiation must be evaluated using a fixing screw made of carbon fiber. In the future, electron generation in aluminum, titanium alloy, and carbon fiber screws must be compared to ascertain the material that can reduce normal tissue exposure. Furthermore, effective methods can be determined by comparing various types of radiation therapy.

\section{Conflicts of Interest}

The authors have nothing to disclose.

\section{Availability of Data and Materials}

All relevant data are within the paper and its Supporting Information files.

\section{Author Contributions}

Conceptualization: Heesoo Kim, Jeong-Woo Lee. Data curation: Heesoo Kim. Formal analysis: Heesoo Kim, JeongWoo Lee. Funding acquisition: N/A. Investigation: Heesoo Kim, Jeong-Woo Lee. Methodology: Heesoo Kim, Jeong-Woo Lee. Project administration: N/A. Resources: N/A. Software: N/A. Supervision: Jeong-Woo Lee. Validation: Heesoo Kim, Jeong-Woo Lee. Visualization: Heesoo Kim. Writing-original draft: Heesoo Kim. Writing-review \& editing: Heesoo Kim, Jeong-Woo Lee.

\section{References}

1. Kim YB, Suh CH. Evolution of radiotherapy: high-precision radiotherapy. J Korean Med Assoc. 2008;51:604-611.

2. Chung HT, Kim DG. Introduction to radiosurgery. J Korean Med Assoc. 2008;51:5-15.

3. Jeon SR, Lee DJ, Kim JH, Kim CJ, Kwon Y, Lee JK, et al. Outcome of gamma knife radiosurgery for trigeminal neuralgia. J Korean Neurosurg Soc. 2000;28:1228-1232.

4. Choi EJ, Ro HW, Cho JS, Park MH, Yoon JH, Jegal YJ. Gamma Knife Surgery for brain metastases from breast carci- noma. J Korean Surg Soc. 2009;76:81-85.

5. Young RF. The role of the gamma knife in the treatment of malignant primary and metastatic brain tumors. CA Cancer J Clin. 1998;48:177-188.

6. Young RF. Radiosurgery for the treatment of brain metastases. Semin Surg Oncol. 1998;14:70-78.

7. Kwon YM, Park YS, Ha Y, Chang JH, Chang JW, Park GY. Factor related to occurrence of radiation necrosis following gamma knife radiosurgery for metastatic brain tumors. Brain Tumor Res Treat. 2004;3:103-108.

8. Lim SM, Lee R, Suh HS. Clinical results from single-fraction stereotactic radiosurgery (SRS) of brain arteriovenous malformation: single center experience. Korean J Med Phys. 2010;23:274-280.

9. Kossert K, Marganiec-Gałązka J, Mougeot X, Nähle OJ. Activity determination of ${ }^{60} \mathrm{Co}$ and the importance of its beta spectrum. Appl Radiat Isot. 2018;134:212-218.

10. Evans LT, Andre K, De R, Henning R, Morgan ED. Reconstruction of a radiation point source's radial location using goodness-of-fit test on spectra obtained from an HPGe detector. Nucl Instrum Methods Phys Res B. 2009;267:36883693.

11. Kuntner C, Auffray E, Lecoq P, Pizzolotto C, Schneegans M. Intrinsic energy resolution and light output of the $\mathrm{Lu}_{0.7} \mathrm{Y}_{0.3} \mathrm{AP}$ :Ce scintillator. Nucl Instrum Methods Phys Res A. 2002;493:131-136.

12. Choi TJ, Kim OB, Joo YK, Suh SJ, Son EI. Determination of stereotactic target position with MR localizer. Korean J Med Phys. 1996;7:67-77.

13. Seo WS, Shin DO, Ji YH, Lim YJ. A study on quality assurance for gamma knife. Korean J Med Phys. 2003;14:184188.

14. Baek SY, Choi JY. Associated factors with pin-fixing \& pin removal pain among patients undergoing gamma knife radiosurgery. Asian Oncol Nurs. 2012;12:323-330.

15. Hwang CH, Im IC, Kim JH. A Monte Carlo study of dose enhancement with kilovoltage and megavoltage photons. J Korean Soc Radiol. 2017;11:87-94.

16. Hwang CH, Kang SS, Kim JH. A Monte Carlo study of secondary electron production from gold nanoparticle in kilovoltage and megavoltage X-rays. J Korean Soc Radiol. 2016;10:152-159.

17. Mesbahi A, Jamali F, Garehaghaji N. Effect of photon beam 
energy, gold nanoparticle size and concentration on the dose enhancement in radiation therapy. Bioimpacts. 2013; 3:29-35.

18. Cheung JY, Yu KN, Chan JF, Ho RT, Yu CP. Dose distribution close to metal implants in Gamma Knife Radiosurgery: a Monte Carlo study. Med Phys. 2003;30:1812-1815.

19. Nakazawa H, Mori Y, Yamamuro O, Komori M, Shibamoto Y, Uchiyama Y, et al. Geometric accuracy of 3D coordinates of the Leksell stereotactic skull frame in 1.5 Teslaand 3.0 Tesla-magnetic resonance imaging: a comparison of three different fixation screw materials. J Radiat Res. 2014;55:1184-1191.

20. ICRU Report 44. Tissue substitutes in radiation dosimetry and measurement. ICRU Report. Bethesda: ICRU. 1989; 44.

21. Al-Dweri FMO, Lallena AM. A simplified model of the source channel of the Leksell Gamma Knife ${ }^{\circledR}$ : testing multisource configurations with PENELOPE. Phys Med Biol. 2004;49:3441-3453.

22. Moskvin V, Timmerman R, DesRosiers C, Randall M, DesRosiers P, Dittmer P, et al. Monte Carlo simulation of the Leksell Gamma Knife ${ }^{\circledR}$ : II. Effects of heterogeneous versus homogeneous media for stereotactic radiosurgery. Phys Med Biol. 2004;49:4879-4895.

23. Ballester F, Granero D, Pérez-Calatayud J, Casal E, Agramunt S, Cases R. Monte Carlo dosimetric study of the BEBIG Co-60 HDR source. Phys Med Biol. 2005;50:N309N316.

24. Vijande J, Granero D, Perez-Calatayud J, Ballester F. Monte Carlo dosimetric study of the Flexisource Co-60 high dose rate source. J Contemp Brachytherapy. 2012;4:34-44.

25. Kang JK, Lee DJ. Development of Monte Carlo simulation code for the dose calculation of the stereotactic radiosurgery. Korean J Med Phys. 2012;23:303-308.

26. Khan FM. Physics of radiation therapy. 4th ed. Philadel- phia: Wolters Kluwer Lippincott Williams \& Wilkins; 2012. 27. Zeverino M, Jaccard M, Patin D, Ryckx N, Marguet M, Tuleasca C, et al. Commissioning of the Leksell Gamma Knife $^{\circledR}$ Icon $^{\text {TM }}$. Med Phys. 2017;44:355-363.

28. Wright G, Harrold N, Hatfield P, Bownes P. Validity of the use of nose tip motion as a surrogate for intracranial motion in mask-fixated frameless Gamma Knife ${ }^{\circledR}$ Icon $^{\text {TM }}$ therapy. J Radiosurg SBRT. 2017;4:289-301.

29. AlDahlawi I, Prasad D, Podgorsak MB. Evaluation of stability of stereotactic space defined by cone-beam CT for the Leksell Gamma Knife Icon. J Appl Clin Med Phys. 2017; 18:67-72.

30. Li W, Bootsma G, Von Schultz O, Carlsson P, Laperriere N, Millar BA, et al. Preliminary evaluation of a novel thermoplastic mask system with intra-fraction motion monitoring for future use with image-guided gamma knife. Cureus. 2016;8:e531.

31. Kang KM, Chai GY, Jeong BG, Ha IB, Park KB, Jung JM, et al. An analysis of intra-fractional movement during image-guided frameless radiosurgery for brain tumor using cyberKnife. Korean J Med Phys. 2012;23:169-176.

32. Ji Y, Chang KH, Cho B, Kwak J, Song SY, Choi EK, et al. Evaluation of set-up accuracy for frame-based and frameless lung stereotactic body radiation therapy. Korean J Med Phys. 2015;26:286-293.

33. Lindtner RA, Schmid R, Nydegger T, Konschake M, Schmoelz W. Pedicle screw anchorage of carbon fiberreinforced PEEK screws under cyclic loading. Eur Spine J. 2018;27:1775-1784.

34. Ringel F, Ryang YM, Kirschke JS, Müller BS, Wilkens JJ, Brodard J, et al. Radiolucent carbon fiber-reinforced pedicle screws for treatment of spinal tumors: advantages for radiation planning and follow-up imaging. World Neurosurg. 2017;105:294-301. 